\title{
First-year university students' perception of chemical bonding and bond energy
}

Iselin Grav Aakre ${ }^{1 *}$, Jonas R. Persson ${ }^{2}$, Hilde Lea Lein ${ }^{1}$ and Per-Odd Eggen ${ }^{2}$

${ }^{1}$ Department of Materials Science and Engineering, NTNU Norwegian University of Science and Technology ${ }^{2}$ Department of Physics, NTNU Norwegian University of Science and Technology

*Corresponding author. E-mail: iselin.g.aakre@ntnu.no

ABSTRACT: First-year university students' knowledge and conceptual understanding of general chemistry has been investigated using a multiple-choice concept inventory (Chemical Concept Inventory 3.0/CCl 3.0) as a pre-test $(n=221)$ and a post-test $(n=90)$ in two first-semester chemistry courses. This paper discusses the students' answers to two questions about bond energy. Student interviews $(n=7)$ were performed for further insight into the students' thought processes and validation of the $\mathrm{CCl}$ questions. Although many students appeared to recall that breaking a chemical bond demands energy, most were not able to use this fact to reason about the heat released in a chemical reaction, and the alternative conception that bond breaking releases energy seemed deeply ingrained and prevalent among the students. For one of the questions, more students gave the correct answer on the pre-test than on the post-test. Student interviews indicated that some students' failure to pick the correct alternative for this question might be influenced by use of the word "always" in the correct answer, which discouraged those students that find chemistry to be a subject full of exceptions.

KEYWORDS: Chemistry education; chemical bonding; bond energy; concept inventories; alternative conceptions

\section{INTRODUCTION}

A chemical bond is a lasting electrostatic attraction that holds the atoms in a chemical compound and components of a solution together. Breaking a bond requires energy. A chemical reaction is what happens when some bonds break and other bonds form. This makes chemical bonding an essential concept in chemistry. However, it is also a complex and abstract concept that is shown to be commonly misunderstood among learners (Taber and Coll, 2002).

This paper investigates university students' conceptual understanding of chemical bonding and bond energy by use of a concept inventory and student interviews and relates the findings to previously published results. The paper seeks to answer the following questions:

1. What are the characteristics of first-year university students' perception of bond energy?

2. Is the students' perception of bond energy coherent or fragmented and/or contradictory?

3. How do the students' perceptions change from the beginning to the end of the course? 


\section{BACKGROUND}

\subsection{ALTERNATIVE CONCEPTIONS RELATED TO CHEMICAL BONDING AND BOND ENERGY}

In constructivist learning theory, the learner constructs her own knowledge system in order to make sense of the world around her (Taber, 2000a). All new information will be interpreted in terms of the learners existing conceptions. Conceptions that differs from the scientifically accepted view, are commonly called alternative conceptions, although a myriad of related terms, such as misconceptions, prior conceptions and incidental knowledge, exist (see e.g. Abimbola, 1988). One or more related alternative conceptions that are applied in several different situations or contexts could be labelled as an alternative framework. Alternative conceptions are resistive to change (Taber, 2001), and chemists have endeavoured to identify common alternative conceptions under the assumption that meaningful teaching should challenge these conceptions explicitly.

Alternative conceptions have been identified in essentially every topic in general chemistry (Garnett, Garnett and Hackling, 1995; Horton, 2007). Chemical bonding is no exception, and alternative conceptions related to fundamental concepts such as why chemical bonds are formed (Taber, 2001), the similarities and distinctions between different categories of chemical bonds (Taber and Coll, 2002), what a chemical bond consists of (Taber, 1997) and how the models used to describe chemical bonding should be used and understood (Coll and Treagust, 2003) appears to be widespread. Relevant review articles about alternative conceptions related to chemical bonding are written by Taber and Coll (2002), Özmen (2004), Ünal et al. (2006) and Levy Nahum et al. (2010). Much of the research focuses on secondary school students, but similar alternative conceptions have been found across several age groups, including university students (Nicoll, 2001; Coll and Taylor, 2002; Coll and Treagust, 2003; Galley, 2004).

Students' conceptions about the relationship between energy and chemical bonding have been investigated by Galley (2004), Barker and Millar (2000) and Boo (1998). Galley (2004) established that the alternative conception that bond breaking is exothermic is remarkably widespread among university students, but can be resolved by informing students of the common misunderstanding and reviewing the nature of a chemical bond on a fundamental level. This alternative conception has also been documented among teenagers (Boo, 1998; Barker and Millar, 2000) and college students (Becker and Cooper, 2014).

Boo (1998) pointed out that energy is a difficult concept to grasp. She used semi-structured interviews and found that almost half of the students (23 of 48) viewed chemical bonds as a physical entity that requires energy to be build and releases energy when broken. A minority of the students expressed that energy is needed both for forming and for breaking chemical bonds. Boo directed attention to the conflict between everyday use and the scientific use of words like bonds and energy as a complicating element. She also found that most of the students did not use their framework consistently.

Barker and Millar (2000) tested 250 students 3 times in the span of 16 months in order to follow their development through a 20 months course. They found that many students envisioned chemical bonding and thermodynamics as separate topics and were unable to 
connect these topics in a satisfying way. At the end of the course, about half of the students had learned that it takes energy to break a chemical bond, while a fifth of the students stayed confident that energy is stored in chemical bonds and released when the bond is broken. Some of the students claimed that bond breaking both demands and releases energy.

\subsection{SOURCES OF ALTERNATIVE CONCEPTIONS}

Alternative conceptions come from different sources. Some alternative conceptions are believed to originate from outside formal education. These conceptions are often called e.g. naïve beliefs, children's science, common-sense concepts or intuitive understanding. Because of the abstract nature of chemical bonding and bond energy, students get little direct experience with these concepts outside of school. For this reason, it is expected that some or most of the students' alternative conceptions are formed during formal education. Alternative conceptions related to chemical bonding and bond energy is documented among teachers in training (Taber, 2000a), and models known to strengthen or introduce alternative conceptions for chemical bonding are common in textbooks (Bergqvist et al., 2013) and teaching (Coll and Treagust, 2003; Bergqvist, Drechsler and Chang Rundgren, 2016). Both chemical bonding and energy is revealed to be difficult topics where alternative conceptions are widespread.

The word "energy" has different meanings in science and in everyday language, which can act as a complicating factor for students (Boo, 1998). Likewise, several terms used in science and chemistry education is easily misinterpreted and may lead to or strengthen the alternative conception that energy is released when chemical bonds are broken. This includes common expressions such as compounds or molecules "contain energy" (Ross, 2013) and "energy stored in chemical bonds" (Galley, 2004). Becker and Cooper (2014) argued that the students' idea that bond breaking is exothermic origins partly from the interpretation of potential energy as stored energy, an interpretation supported by curricula and textbooks. They recommended highlighting the role of electrostatic forces and emphasising that potential energy is stored in interactions between particles.

The term high-energy bond was introduced by Fritz Albert Lipmann (1899-1986) to describe bonds in the molecule adenosine triphosphate (ATP) and is commonly used in biology. Concerns about the use of this term have been raised several times (Cohen and Ben-Zvi, 1982; Hanson, 1989; Galley, 2004; Ross, 2013). Despite these concerns, ATP is often described in textbooks and elsewhere as an energy source or an energy-carrying molecule, and the bond is labelled a high-energy bond. International textbooks used in basic chemistry courses also use potentially problematic language such as describing ATP as an energy-rich molecule or compound (Brown et al., 2008, p. 1103; Tro, 2017, p. 921), an energy source (Tro, 2017, p. 921) or an energy store (Brown et al., 2008, p. 959; Housecroft and Constable, 2010, p. 1246; Burrows et al., 2013, p. 682), and as containing high-energy bonds (Petrucci et al., 2011, p. 1288). However, some chemistry textbooks do problematise use of the term high-energy bonds (Mahaffy et al., 2014, p. 244).

The Norwegian term for high-energy bonds is energy-rich bonds ("energirike bindinger"). This term is mentioned in several of the textbooks used in Norwegian schools. In lower secondary 
level the term is mainly used for describing entire molecules or substances, e.g. food or fuel is described as energy-rich, while it is used to describe specific chemical bonds in textbooks for upper secondary level (Mæland, 2013). The term is also used in Norwegian university-level chemistry textbooks (Steen, 2014, pp. 579-580).

\subsection{CONTRADICTIONS IN THE STUDENTS' FRAMEWORKS}

Students providing self-contradictory answers or explanations seems to be a common occurrence, as shown in part 1.1 above. Some of the literature on chemistry education expand on this. Palmer (2003) referenced multiple sources suggesting that even though students seem inconsistent from a scientific point of view, they might still be consistent from their own point of view. Watson, Prieto and Dillon (1997) provided three possible explanations for such apparent contradictions in students' frameworks: (1) the students may be consistent from their viewpoint even though they seem inconsistent from the researcher's viewpoint, (2) the students frameworks may be limited in scope, or (3) the students may be in transition from one framework to another.

Pope and Denicolo (1986) agreed that self-contradictions may origin from multiple frameworks, and Taber (2000b) argued that multiple frameworks are to be expected among chemistry students. Taber wrote about a student, Tajinder, and his use of multiple frameworks for explaining chemical bonding:

If Tajinder was expected to accept that oxidation may be the addition of an oxygen atom, the loss of an electron, or an increase in the number (oxidation state) assigned according to a list of rules: why should bonding not be variously explained as obtaining a full shell, minimizing energy or the effects of electrostatic forces? (Taber, 2000b, p. 413)

Taber claimed that a learner may simultaneously hold several alternative frameworks about the same concept and use the one they find most appropriate for any given case. Some studies suggest that students only, or more often, apply the scientific explanation if the question has an obvious scientific context, while they use their alternative frameworks in more "everyday" contexts (Taber, 2000b).

Self-contradictions can be viewed as an opportunity for conceptual change. If the students are made aware of the self-contradictory nature of their beliefs, this could motivate the students to change their beliefs. For this reason, Teichert and Stacy (2002) presented a discussion-based intervention about bond energy where the instructor's role is not to explain, but rather to make the students aware of their own contradictory conceptions under the assumption that some initial confusion will help enhance learning and remove inconsistencies.

This study investigates first-year university students' conceptions about bond energy at the beginning and at the end of a one-semester basic chemistry course. We were particularly interested in unveiling whether the students' understanding of the topic was scientific and coherent or fragmented and contradictory. 


\subsection{CONCEPT INVENTORIES AND MULTIPLE-CHOICE TESTING}

A concept inventory is an assessment tool, often in the form of a multiple-choice test, that measures understanding of chosen concepts and phenomena. Concept inventories are based on constructivist theory, and by using known alternative conceptions as distractors, a concept inventory can map both students' understanding and common alternative conceptions (Adams and Wieman, 2011). Although interviews or open-ended questions may give a deeper insight into a student's conceptions, multiple-choice concept inventories provide a practical, scalable, reliable and effective method for mapping the conceptions of a large number of students at the same time.

One of the most famous concept inventories is the Force Concept Inventory ( FCl) (Hestenes, Wells and Swackhamer, 1992), which has been used in Physics for decades. In chemistry, different concept inventories have been developed (Mulford and Robinson, 2002; Krause et al., 2004), with none of them becoming as widespread as the $\mathrm{FCl}$. Concept inventories about specific topics in chemistry, among them chemical bonding (Peterson, Treagust and Garnett, 1986; Othman, Treagust and Chandrasegaran, 2008; Şen and Yilmaz, 2017), has also been developed.

Multiple-choice testing has been criticised for giving somewhat random results and rewarding guesswork. The wording of the questions (Cassels and Johnstone, 1984) or even the arrangement of the alternative answers (Johnstone and Ambusaidi, 2000) may influence the students' answers. Test-wiseness strategies are strategies for answering multiple-choice questions that require little or no knowledge of the relevant topic. Students' use of testwiseness strategies in chemistry have been little investigated, but some patterns in students' wrong answers have been revealed (Schmidt, 1988). Students of general chemistry appear to use similar test-wiseness strategies as students of other subjects, and most of the strategies used do not threaten the validity of the multiple-choice tests (Towns and Robinson, 1993). A much-used strategy is elimination of (assumed) wrong answers.

\section{METHOD}

A concept inventory for general chemistry (Chemical Concept Inventory, $\mathrm{CCl} 3.0$ ) was developed at the Norwegian University of Science and Technology (NTNU) in 2015. The CCI 3.0 has been statistically tested (Eggen et al., 2017) and used as both pre-test at the beginning of the semester and post-test after the teaching of the course in several chemistry courses at NTNU. A Finnish version of the concept inventory has been used at the University of Jyväskylä, Finland (Kiviniemi et al., 2018; Kiviniemi and Nuora, 2020). Please contact the corresponding author for access to the Norwegian version of $\mathrm{CCl} 3.0$.

The $\mathrm{CCl} 3.0$ consists of 40 multiple-choice questions and is estimated to take 45 minutes. This paper discusses the test results from students in two first-semester chemistry courses in autumn 2016. These courses are intended for students in the first semester of the first year in five-year programs in Master of Engineering. Both courses cover basic chemistry, are 7.5 ECTS, and have similar, but not identical, intended learning outcomes. Course 1 is administered to 
students studying petroleum and geology, and course 2 is intended for chemical engineering students. Course 2 includes laboratory work. The Master of Engineering programs on NTNU are popular, and the students have high overall grades from upper secondary school. Except general science, no background in chemistry is required for admittance. However, $30 \%$ of these students have one year and $47 \%$ of the students have two years of chemistry courses from upper secondary school. Most of the students are 18-21 years old when starting their university studies. The test was given in Norwegian in scheduled lectures in the beginning (pre-test) and end (post-test) of the course. The tests were voluntary for the students, who answered anonymously. This made it impossible to compare pre-test and post-test results for individual students. The professors teaching the courses were not involved in the development of the $\mathrm{CCl}$ 3.0, and were unaware of the research questions formulated in this paper. The authors of this paper were not involved in the teaching of the courses.

Figure 1 shows question 1 (Q1), a question that was created during the development of the $\mathrm{CCl} 3.0$ and given as question 33 of 40 on the test. The correct answer is alternative A. This question investigates the students' conceptions about the energy change related to bond breaking, and more specifically when the bond in ATP commonly referred to as a high-energy bond is broken. It was assumed that a significant portion of students had previously seen ATP described in such a way and that some of these students would choose the distractor B.

The picture shows an ATP molecule with one bond marked with an arrow. Which statement is TRUE?<smiles></smiles>

A) It always takes energy to break a bond. This is also true for this bond.

B) It takes energy to break most bonds, but this is a high-energy bond that releases energy when it is broken

C) All bonds release energy when they are broken

D) It takes energy to break covalent bonds, but this is an ionic bond, and they release energy when they are broken.

Figure 1: Question 1 (Q1). The correct answer is alternative A. The question has been translated into English by the authors, see Appendix 1 for the original Norwegian version.

The second question (Q2) is adapted from another chemistry concept inventory (Mulford and Robinson, 2002). During translation from English to Norwegian and the development of the $\mathrm{CCl} 3.0$, the wording has been somewhat changed. The English version given in Figure 2 is 
aiming to be as true to the Norwegian version (see Appendix 1 ) as possible and differs slightly from the wording of the question previously published by Mulford and Robinson. The main difference is that the question in the $\mathrm{CCl} 3.0$ only refers to heat being released, while the wording in Mulford and Robinson refers to heat in the question and energy in the alternatives. No explanation for the relationship between heat and energy is provided in either of the versions. This question was given as question 39 of 40 on the $\mathrm{CCl}$ 3.0. Mulford and Robinson used the question as number 9 of 22 on their concept inventory. The correct answer $C$ states that heat is released when bonds are formed, whereas the distractors A, B and D all claim that heat is released then bonds are broken. The distractor $E$ claims that heat is released both when bonds are broken and when they are formed.

Heat is released when hydrogen burns in air according to the equation:

$$
2 \mathrm{H}_{2}+\mathrm{O}_{2} \rightarrow 2 \mathrm{H}_{2} \mathrm{O}
$$

What is the reason for heat to be released?

A) When the hydrogen bonds are broken, heat is released.

B) When the bonds in oxygen are broken, heat is released.

C) When the bonds between hydrogen and oxygen are formed, heat is released.

D) Both $a$ and $b$ are correct.

E) Both $\mathrm{a}, \mathrm{b}$ and $\mathrm{c}$ are correct.

Figure 2: Question 2 (Q2). The correct answer is alternative C. The question has been translated from Norwegian to English by the authors, see Appendix 1 for the original Norwegian version. A similar question is used in a concept inventory previously

As recommended in the literature (Adams and Wieman, 2011), student interviews were performed to validate the $\mathrm{CCl} 3.0$ answers. Seven engineering students from four study programmes at NTNU including both five-year Master of Engineering and three-year Bachelor of Engineering were interviewed. The students were currently studying three different chemistry courses taught by different lecturers, and all of them had some chemistry background from upper secondary school. Both genders were represented, and the age span of the students reflected the age span of the student group. When asked about their opinion of chemistry, two of the students described it as positive, three as neutral and two as negative. The interviews took place at the end of the spring semester in 2019 but before the final exam. None of the interviewed students had taken the $\mathrm{CCl} 3.0$ previously.

The interviews used a think-aloud protocol (Ericsson and Simon, 1998; Adams and Wieman, 2011) where the students were given six questions including the alternative answers from the $\mathrm{CCl}$ 3.0. Q1 and Q2 were given as the fourth and sixth question, respectively. The other four questions were included to get the students used to the interview setting and the think-aloud protocol. All students were given the same questions in the same order, one question at a time. According to the think-aloud protocol, the students were asked to think aloud while answering the questions as they would have done in a test situation, without explaining their thoughts. The researcher observed and took notes without interfering, except in the rare instances when 
the student was silent for a significant time, and the researcher reminded the student to share his or her thoughts. Additional questions about the student's choices and reasoning were given after all 6 questions were answered.

Extensive notes were taken from the interviews and compared to the question sheets with the students' notes and drawings. Each interview lasted for approximately 45 minutes, including a general introduction and the opportunity to discuss the correct answers to the questions at the end of the interview, an opportunity that all seven students expressed an interest in. The interviews were conducted and analysed by the first author of this paper. The excerpts from the interviews given in part 4 below have been translated from Norwegian by the first author. The Norwegian version is given in Appendix 2. The interviews and interview protocol were approved by the Norwegian Centre for Research Data (NSD), reference number 763912.

\section{RESULTS}

Table 1 gives the results from the $\mathrm{CCl} 3.0$ for the two chemistry courses and shows the number of answers, percentage correct answer for the two selected questions, and the average total test score. The table shows some differences between the student groups, but also strong similarities. The difference in average test score between the two student populations is insignificant on a 0.05 significance level. For this reason, and because the aim is not to compare the two courses, the results from both courses are pooled in the rest of the paper.

Table 1: Results from the CCl 3.0 in two chemistry courses given autumn 2016. The highest possible test score is 40.

\begin{tabular}{|c|c|c|c|c|c|c|}
\hline & \multirow{2}{*}{$\begin{array}{c}\text { Number of } \\
\text { students }\end{array}$} & \multicolumn{2}{|c|}{$\%$ correct } & \multirow{2}{*}{$\begin{array}{l}\text { \% both } \\
\text { correct }\end{array}$} & \multirow{2}{*}{$\begin{array}{l}\text { \% both } \\
\text { wrong }\end{array}$} & \multirow{2}{*}{$\begin{array}{l}\text { Average test score } \\
\text { (standard deviation) }\end{array}$} \\
\hline & & Q1 & Q2 & & & \\
\hline Course 1 pre & 149 & 52.3 & 32.2 & 21.5 & 36.9 & $19.1(6.8)$ \\
\hline Course 2 pre & 72 & 41.7 & 33.3 & 22.2 & 47.2 & $20.7(6.3)$ \\
\hline Total pre & 221 & 48.9 & 32.6 & 21.7 & 40.3 & $19.6(6.6)$ \\
\hline Course 1 post & 47 & 40.4 & 38.3 & 14.9 & 36.2 & $22.8(6.6)$ \\
\hline Course 2 post & 43 & 32.6 & 34.9 & 16.3 & 48.8 & $21.0(5.7)$ \\
\hline Total post & 90 & 36.7 & 36.7 & 15.6 & 42.2 & $21.9(6.2)$ \\
\hline
\end{tabular}

The overall average test score is 20.3 out of 40 , and the total sample standard deviation is 6.6. This means that the average student picked the correct answer about half the time, but that many students performed considerably better or worse than this. There is a significant increase in the average test score from the pre-test to the post-test, but the effect is only moderate ( $p$-value $<0.005$, Cohen's $d=0.37)$.

More students give the correct answer on Q1 than on Q2. Only $20 \%$ of the students answer both questions correctly. This number is lower for the post-tests than for the pre-tests, but the change is not significant using $\alpha=0.05 .41 \%$ of the students answer both questions wrong. This number differs between the student groups but changes little from the pre-test to the posttest. 
The tests were voluntary, and the number of participating students is higher for the pre-tests than the post-tests. Of the 189 students registered in course 1, $79 \%$ answered the pre-test but only $25 \%$ answered the post-test. For course 2, $55 \%$ of the 131 students answered the pre-test and $33 \%$ answered the post-test.

A comparison of the pre-test results and the post-test results for the student responses to Q1 is shown in Figure 3. Students that did not answer the question are excluded from the calculated percentages. The distractors $C$ and $D$ show little change from the pre-test to the post-test, but there is a decrease in the portion of students that answer the correct alternative $A$ and an even bigger increase in the portion of students that answer the distractor $B$. Both the decrease in the percentage of correct answers Q1 A and increase in the percentage of wrong answers Q1 B are significant with $\alpha=0.05$.

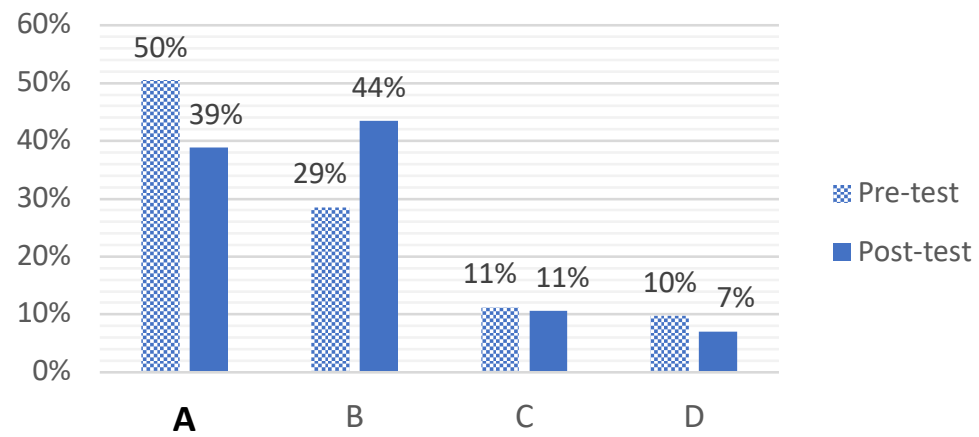

Figure 3: Student responses to question 1 on the pre-test and the post-test. The correct answer is alternative A.

Figure 4 compares the pre-test and post-test results for the student responses to Q2 from NTNU with the results reported by Mulford and Robinson (2002). Students that did not answer the question are excluded from the calculated percentages. The data from Mulford and Robinson (MR) is based on answers from 928 first-year university students answering both the pre-test and the post-test at a Midwestern university in the USA. There are clear similarities between the two student populations, especially in the direction of the change from the pretest to the post-test. The main differences are that while about one-fifth of the American students answer the distractor B, this is the least popular answer among the Norwegian students and that the Norwegian students have an even larger tendency to answer either the correct answer $\mathrm{C}$ or the distractor $\mathrm{D}$ than the American students have. This is true for both the pre-test and the post-test. 


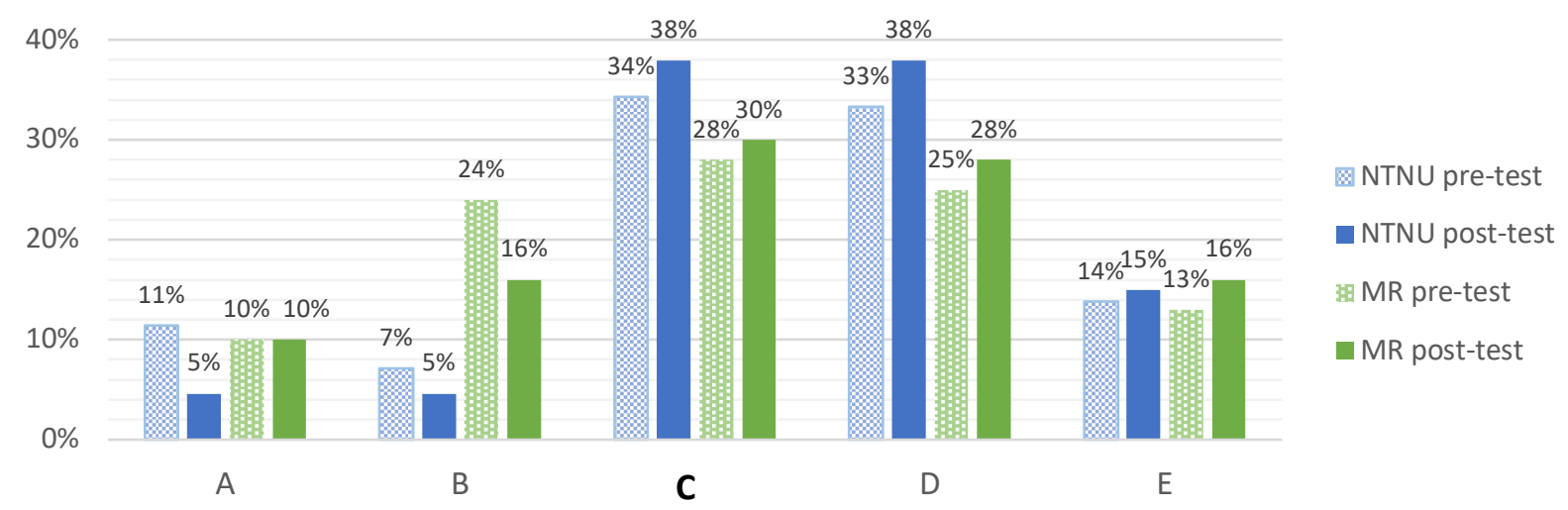

Figure 4: Student responses to question 2 on the pre-test and the post-test. Data from NTNU (blue) and Mulford and Robinson (2002) (MR, green). The correct answer is alternative $C$.

The interviews did not reveal any threats to the validity of the questions or show any obvious misinterpretations of the way the questions were intended to be understood. They did, however, provide useful material for interpreting the $\mathrm{CCl}$ results, as will be shown in the discussion below. 3 of the 7 interviewed students answered Q1 correctly, and 3 students answered Q2 correctly. None of the interviewed students answered both Q1 and Q2 correctly.

\section{DISCUSSION AND INTERVIEW FINDINGS}

\subsection{WHY DO THE STUDENTS STRUGGLE WITH QUESTION 1?}

The portion of students answering question 1 correctly, decreases from the pre-test to the post-test (see Table 1 and Figure 3). This is true for both courses and suggests that the courses have failed to address the alternative conception that the high-energy bond in ATP releases energy when broken. There are, however, other possible explanations. Instead of there being a true decrease in the portion of the students able to answer the question correctly, the change could be due to diverse populations. Fewer students answer the post-test than the pre-test, and the difference is particularly large for course 1 . The total test score increases slightly from the pre-test to the post-test, which means that the students answering the post-test, in general, have a better understanding of chemical concepts than the students answering the pre-test. Nevertheless, further analysis of the data shows that students who know that it always takes energy to break a chemical bond ( $Q 1 \mathrm{~A}$, correct) do not perform statistically significant better on the test than students believing that there are exceptions to the rule (distractor Q1 B), or the opposite, that bond breaking releases energy, is true (distractor Q1 C).

According to the professor teaching one of the courses, bond energy has almost no focus in these courses. Although bond energy is described in the textbook (Petrucci et al., 2011 pp. 450453), it is hardly discussed in lectures and exercises. This may be one of the reasons for the lack of a positive correlation between a correct answer to question 1 and the total test score, at least for the post-test, but raises some interesting questions: Does the teaching of general chemistry somehow strengthen the conception that bond breaking may be exothermic, even without mentioning bond energy? And if so, why? 
The interviews suggest that the main reason why the students chose the distractor Q1 B is that they eliminated the other alternatives, including the correct answer Q1 A. Some students were discouraged by the absolute wording of alternative Q1 A. One student expressed a distaste for the word "always": "“Always" is kind of a don't-word, so I doubt that one immediately." Another student found alternative Q1 A unrealistic: "No, I think we take B. It seems more ... sensible. I don't ... I sort of think it is A, but B seems much more ... sensible, yes. Much more realistic." These students felt that Q1 B was a safer choice than Q1 A because alternative Q1 B left some room for exceptions.

There is an exception to every rule - or so the students seemed to think. A possible consequence of the notion that chemistry is a subject full of inconsistencies and exceptions, could be that the students focus on learning specific algorithms instead of trying to understand the basic principles behind more general rules. Carter and Brickhouse (1989) found that many of their students ranked "too many exceptions to the rules" as a hindrance to learning chemistry. If indeed the increase in the portion of students answering Q1 B from the pre-test to the post-test is due to more students finding chemistry a subject full of inconsistencies and exceptions at the end of the semester, this is concerning and should be addressed in the teaching of the courses in the future.

The term high-energy bond ("energirik binding" /"energy-rich bond") did not seem familiar to any of the interviewed students, and there is no mentioning of ATP or biochemistry on the course syllabi. However, for at least one of the students, this only made the distractor Q1 B more inviting: "I have never really heard the word high-energy bond before, so my gut feeling kind of want to choose that one, because I have never gotten a question like this before." In the informal part of the interview after the test questions, some of the students acknowledged that they found it a bit daunting to be presented with a complex structural formula. This might have accentuated the scientific context of the question and made the scientific-sounding term highenergy bond more alluring.

\subsection{THE WORDING OF QUESTION 2}

Although the wording of the distractors Q2 A and Q2 B may seem similar, to a chemist they are clearly different: Q2 A concerns intermolecular hydrogen bonds, whereas Q2 B concerns intramolecular and strong oxygen bonds (see Figure 2 ). This could possibly confuse students (Venkataraman, 2017), but there was no evidence of this in the interviews. On the contrary, the students seemed to immediately perceive "hydrogen bonds" as intramolecular bonds between hydrogen atoms. Based on this, it seems probable that the student responses will stay relatively constant if the distractor Q2 A is changed to "When the bonds in hydrogen are broken, heat is released" to better match the wording of the distractor Q2 B.

Most of the students chose either the correct alternative Q2 C or the distractor Q2 D (see Figure 4). While Q2 C correctly states that heat is released when bonds are formed, Q2 D represents the opposite claim. Q2 C and Q2 D have a similar popularity. This opens the possibility that the students simply pick between these answers randomly, as that would give a 
comparable distribution. The interviews prove this explanation to be unsatisfactory, as the students do argue for which of the processes that they believe will release heat.

In contrast to the version published by Mulford and Robinson (2002), the Norwegian version of this question only mentions heat and not energy. However, the interviews did not show this to be problematic for the students. Most of the students (5 out of 7) used the word "energy" during the think-aloud process while solving question 2, and none of the students seemed to presume there to be any difference between the heat released and the energy released. Because of this, the student responses to Q2 are assumed to be related to the students' perception of bond energy.

\subsection{THE (LACK OF) CONNECTION BETWEEN A STUDENT'S ANSWER TO Q1 AND Q2}

More students answer Q1 correctly than Q2. Assuming the students make the connection between energy and heat, all students that answer Q1 correctly ("It always takes energy to break a bond") should also answer Q2 correctly (heat is released when bonds are formed, not when bonds are broken). This is, however, far from the case. Table 1 shows that $33.8 \%$ of all students answer Q2 correctly. Further analysis reveals that only $44.0 \%$ of the students that answer Q1 correctly also answers Q2 correctly. This percentage changes little from the pre-test to the post-test. In plain words: a significant portion of the students - more than half of those that answer Q1 correctly - contradict themselves. This implies that the students lack a consistent framework for chemical bonding and bond energy, and confirms the findings previously reported by Boo (1998) and Barker and Millar (2000). One possible reason for apparent contradictions in the students' frameworks is that the students may be consistent from their viewpoint even though they seem inconsistent from the researcher's viewpoint (Watson, Prieto and Dillon, 1997). In the case of multiple-choice testing this reason may be enhanced by the fact that the students get no opportunity to explain their rationale to the researcher.

This apparent contradiction was also present in the interviews where 3 students answered Q1 correctly and Q2 wrongly. An example of correct reasoning on Q1, although with some expressed self-doubt: "I think energy is needed to break all bonds, if not they would just fall apart, maybe." Another student wondered: "Are there any bonds that don't need energy to break? I don't think so." But later, when deciding on the answer to Q2, the same student stated: "I think that when the bonds are formed, it is an endothermic reaction, it needs energy. When they are broken, it is an exothermic reaction."

For some students, "It always takes energy to break a bond" (alternative Q1 A) appears to be a learned fact that they fail to apply in relevant situations, in this case the reaction between hydrogen gas and oxygen gas (Q2). According to the information processing model presented by Johnstone (1997), failure to apply a known fact in a given situation may be due to the knowledge being stored in the students' long term memory as a separate fragment. Without sufficient links to other information in the long-term memory, the retrieval of the information in relevant situations is somewhat up to chance. In other words, the students' failure to apply a useful explanation could be due to them having several incomplete or fragmented frameworks 
instead of one comprehensive, coherent framework. As mentioned earlier, some studies suggest that students only, or more often, apply the scientific explanation if the question has an obvious scientific context, but tend to fall back on their alternative frameworks in more "everyday" contexts (Taber, 2000b). In question 1, the structural formula and name-dropping of ATP and high-energy bonds may have fortified the scientific nature of the question. Question 2 might have appeared like a less scientific question to the students because of their familiarity with the reactants, product and reaction. The interviews revealed that some of the students focused on their own experiences with the hydrogen-oxygen reaction that they had earlier seen demonstrated. The contradiction could be interpreted as evidence that the alternative conception of exothermic bond breaking is deeply ingrained in the students, and that even the students who know that the opposite is true, fall back on this alternative conception in different contexts.

Table 1 shows that the percentage of students that answer both Q1 and Q2 wrongly is quite high and that it stays remarkably constant for both student groups from the pre-test to the post-test. The data is anonymous and does not track the students from the pre-test to the posttest. This is unfortunate, as it would be interesting to see if the same students answer both questions wrongly on the pre-test and on the post-test and if there are any patterns in how the students change their answers. The percentage of students that answer both questions correctly decreases from the pre-test to the post-test, but the change is not significant. A similar trend is found by Othman, Treagust and Chandrasegaran (2008), who compared Grade 9 students' and Grade 10 students' responses to conceptually related items in their concept inventory and found the percentage of students answering both related questions correctly did not increase from Grade 9 to Grade 10.

\section{CONCLUDING COMMENTS}

It takes energy to break a chemical bond. Data from the $\mathrm{CCl} 3.0$ and student interviews indicates that despite little focus on bond energy in these courses, most students knew this fact, although many students believed that there might be some exceptions. However, when the question demanded them to apply this fact to a chemical reaction, most of the students failed to do so and answered as if they presumed bond breaking to be exothermic. This implies that many students are confused about bond energy and lack a coherent framework for chemical bonding and bond energy. The confusion manifested itself by the fact that only a small percentage of the students answered both questions correctly, and that many students contradicted themselves.

The contradictions in the students' answers were prevalent also at the end of a university-level basic chemistry course. The alternative conception that bond breaking releases energy appear to be so ingrained in the students, that even a majority of the students who knew the opposite to be true, contradicted themselves in their test answers. Alternative conceptions can origin from a myriad of sources, and for relative abstract topics such as chemical bonding and bond energy it is probable that at least some of them come from formal science education. However, 
the alternative conception of exothermic bond energy might also stem from everyday language and expressions.

A new national curriculum for Norwegian schools will be implemented in part from the academic year 2021/2022. The new curriculum for Chemistry on upper secondary school level describes chemical bonding as "electrostatic forces that act between particles" (Utdanningsdirektoratet, 2021, translated into English by the authors). This change is in part inspired by the findings discussed in this paper. It will be interesting to examine whether the students' conceptual understanding of chemical bonding and bond energy will improve after the implementation of the new curriculum.

The percentage of students that answered question 1 about ATP correctly, decreased from the pre-test to the post-test. Interviews revealed that some students wanted to avoid absolutes in their answers, possibly because they find chemistry to be a subject full of exceptions and inconsistencies. It would be interesting to compare pre- and post-data from the $\mathrm{CCI} 3.0$ on an individual level to examine which students change their answers and how, and how the students' $\mathrm{CCl}$ results correlate to their exam result. This is planned as a future study.

\section{REFERENCES}

Abimbola, I. O. (1988) 'The problem of terminology in the study of student conceptions in science', Science Education, 72(2), pp. 175-184. doi: 10.1002/sce.3730720206.

Adams, W. K. and Wieman, C. E. (2011) 'Development and Validation of Instruments to Measure Learning of Expert-Like Thinking', International Journal of Science Education, 33(9), pp. 1289-1312. doi: 10.1080/09500693.2010.512369.

Barker, V. and Millar, R. (2000) 'Students' reasoning about basic chemical thermodynamics and chemical bonding: What changes occur during a context-based post-16 chemistry course?', International Journal of Science Education, 22(11), pp. 1171-1200. doi: $10.1080 / 09500690050166742$.

Becker, N. M. and Cooper, M. M. (2014) 'College chemistry students' understanding of potential energy in the context of atomic-molecular interactions', Journal of Research in Science Teaching, 51(6), pp. 789-808. doi: 10.1002/tea.21159.

Bergqvist, A. et al. (2013) 'Representations of chemical bonding models in school textbookshelp or hindrance for understanding?', Chemistry Education Research and Practice, 14(4), pp. 589-606. doi: 10.1039/c3rp20159g.

Bergqvist, A., Drechsler, M. and Chang Rundgren, S. N. (2016) 'Upper Secondary Teachers' Knowledge for Teaching Chemical Bonding Models', International Journal of Science Education, 38(2), pp. 298-318. doi: 10.1080/09500693.2015.1125034.

Boo, H. K. (1998) 'Students' Understandings of Chemical Bonds and the Energetics of Chemical Reactions', Journal of Research in Science Teaching, 35(5), pp. 569-581. doi: 10.1002/(SICI)1098-2736(199805)35:5<569::AID-TEA6>3.0.CO;2-N.

Brown, T. E. et al. (2008) Chemistry. The central science. 11th ed. Pearson.

Burrows, A. et al. (2013) Chemistry3. Introducing inorganic, organic and physical chemistry. 2nd ed. Oxford: Oxford University Press. 
Carter, C. S. and Brickhouse, N. W. (1989) 'What Makes Chemistry Difficult?', Journal of Chemical Education, 66(3), pp. 223-225. doi: 10.1021/ed066p223.

Cassels, J. R. T. and Johnstone, A. H. (1984) 'The effect of language on student performance on multiple choice tests in chemistry', Journal of Chemical Education, 61(7), pp. 613-615. doi: 10.1021/ed061p613.

Cohen, I. and Ben-Zvi, R. (1982) 'Chemical energy: A learning package', Journal of Chemical Education, 59(8), pp. 656-658. doi: 10.1021/ed059p656.

Coll, R. K. and Taylor, N. (2002) 'Alternative Conceptions of Chemical Bonding Held by Upper Secondary and Tertiary Students', Research in Science \& Technological Education, 19(2), pp. 171-191. doi: 10.1080/02635140120057713.

Coll, R. K. and Treagust, D. F. (2003) 'Investigation of secondary school, undergraduate, and graduate learners' mental models of ionic bonding', Journal of Research in Science Teaching, 40(5), pp. 464-486. doi: 10.1002/tea.10085.

Eggen, P.-O. et al. (2017) 'Development of an Inventory for Alternative Conception Among Students in Chemistry', LUMAT: International Journal on Math, Science and Technology Education, 5(1), pp. 1-11. doi: 10.31129/LUMAT.5.1.115.

Ericsson, K. A. and Simon, H. A. (1998) 'How to Study Thinking in Everyday Life: Contrasting Think-Aloud Protocols With Descriptions and Explanations of Thinking', Mind, Culture, and Activity, 5(3), pp. 178-186. doi: 10.1207/s15327884mca050_3.

Galley, W. C. (2004) 'Exothermic Bond Breaking: A Persistent Misconception', Journal of Chemical Education, 81(4), pp. 523-525. doi: 10.1021/ed081p523.

Garnett, Pamela J., Garnett, Patrick J. and Hackling, M. W. (1995) 'Students' alternative conceptions in chemistry: A review of research and implications for teaching and learning', Studies in Science Education, 25(1), pp. 69-96. doi: 10.1080/03057269508560050.

Hanson, R. W. (1989) 'The role of ATP in metabolism', Biochemical Education, 17(2), pp. 86-92. doi: 10.1016/0307-4412(89)90012-5.

Hestenes, D., Wells, M. and Swackhamer, G. (1992) 'Force concept inventory', The Physics Teacher, 30(3), pp. 141-158. doi: 10.1119/1.2343497.

Horton, C. (2007) 'Alternative Conceptions in Chemistry', California Jornal of Science Education, $7(2)$, pp. 18-28.

Housecroft, C. E. and Constable, E. C. (2010) Chemistry. 4th Ed. Pearson Education Limited. Johnstone, A. H. (1997) 'Chemistry Teaching - Science or Alchemy? 1996 Brasted Lecture', Journal of Chemical Education, 74(3), pp. 262-268. doi: 10.1021/ed074p262.

Johnstone, A. H. and Ambusaidi, A. (2000) 'Fixed response: What are we testing?', Chemistry Education: Research and Practice in Europe, 1(3), pp. 323-328. doi: 10.1039/B0RP90014A.

Kiviniemi, T. et al. (2018) 'Development of a chemistry concept inventory for general chemistry students at Norwegian and Finnish universities', in Pálsdóttir, A. (ed.) Science competencies for the future. Proceedings of the 12th Nordic Research Symposium on Science Education, pp. 73-79.

Kiviniemi, T. and Nuora, P. (2020) 'Evaluation of a Chemistry Concept Inventory for general chemistry students at Finnish university', NorDiNa Nordic Studies in Science Education, 16(2), pp. 138-148. doi: 10.5617/nordina.7014. 
Krause, S. et al. (2004) 'Development, Testing, and Application of a Chemistry Concept Inventory', in 34th ASEE/IEEE Frontiers in Education Conference. Savannah. doi: 10.1109/FIE.2004.1408473.

Levy Nahum, T. et al. (2010) 'Teaching and learning the concept of chemical bonding', Studies in Science Education, 46(2), pp. 179-207. doi: 10.1080/03057267.2010.504548.

Mæland, B. (2013) Begrepet energi i norske lærebøker i naturfag. Universitetet i Oslo. Available at: https://www.duo.uio.no/bitstream/handle/10852/36175/Masteroppgave_BjornarMaeland.pdf.

Mahaffy, P. et al. (2014) Chemistry. Human activity, chemical reactivity. 2nd ed. Nelson Canada.

Mulford, D. R. and Robinson, W. R. (2002) 'An Inventory for Alternate Conceptions among FirstSemester General Chemistry Students', Journal of Chemical Education. UTC, 79(6), pp. 739-744. doi: 10.1021/ed079p739.

Nicoll, G. (2001) 'A report of undergraduates' bonding misconceptions', International Journal of Science Education, 23(7), pp. 701-730. doi: 10.1080/09500690010025012.

Othman, J., Treagust, D. F. and Chandrasegaran, A. L. (2008) 'An investigation into the relationship between students' conceptions of the particulate nature of matter and their understanding of chemical bonding', International Journal of Science Education, 30(11), pp. 1531-1550. doi: 10.1080/09500690701459897.

Özmen, H. (2004) 'Some Student Misconceptions in Chemistry: A Literature Review of Chemical Bonding', Journal of Science Education and Technology, 13(2), pp. 147-159. doi: 10.1023/B:JOST.0000031255.92943.6d.

Palmer, D. H. (2003) 'Investigating the Relationship Between Refutational Text and Conceptual Change', Science Education, 87(5), pp. 663-684. doi: 10.1002/sce.1056.

Peterson, R., Treagust, D. and Garnett, P. (1986) 'Identification of secondary students' misconceptions of covalent bonding and structure concepts using a diagnostic instrument', Research in Science Education, 16(1), pp. 40-48. doi: 10.1007/BF02356816.

Petrucci, R. H. et al. (2011) General Chemistry: Principles and Modern Applications. 10th ed. Pearson Prentice Hall.

Pope, M. and Denicolo, P. (1986) 'Intuitive Theories: a Researcher's Dilemma: some practical methodological implications', British Educational Research Journal, 12(2), pp. 153-166. doi: 10.1080/0141192860120205.

Ross, K. A. (2013) 'Fuel and food are not made of energy - a constructive view of respiration and combustion', School Science Review, 94(349), pp. 60-69.

Schmidt, H.-J. (1988) 'Mind the Red Herrings - Deliverate Distraction of Pupil's Strategies Solving Multiple Choice Questions in Chemistry', in Paper presented at the annual meeting of the National Association for Research in Science Teaching. Lake of the Ozarks. Available at: https://files.eric.ed.gov/fulltext/ED291577.pdf.

Şen, Ş. and Yilmaz, A. (2017) 'The development of a three-tier chemical bonding concept test', Journal of Turkish Science Education, 14(1), pp. 110-126. doi: 10.12973/tused.10193a.

Steen, B. G. (2014) Himmelsk kjemi. Innføring i generell og organisk kjemi. 2. utgave. Cappelen Damm Akademisk.

Taber, K. S. (1997) 'Student understanding of ionic bonding: molecular versus electrostatic framework?', School Science Review, 78(285), pp. 85-95.

Taber, K. S. (2000a) 'Chemistry lessons for universities?: a review of constructivist ideas', 
University Chemistry Education, 4(2), pp. 63-72.

Taber, K. S. (2000b) 'Multiple frameworks?: Evidence of manifold conceptions in individual cognitive structure', International Journal of Science Education, 22(4), pp. 399-417. doi: 10.1080/095006900289813.

Taber, K. S. (2001) 'Shifting sands: A case study of conceptual development as competition between alternative conceptions', International Journal of Science Education, 23(7), pp. 731-753. doi: 10.1080/09500690010006572.

Taber, K. S. and Coll, R. K. (2002) 'Bonding', in Gilbert, J. K. et al. (eds) Chemical Education: Towards Research-based Practice. Dordrecht: Kluwer Academic Publishers, pp. 213-234.

Teichert, M. A. and Stacy, A. M. (2002) 'Promoting Understanding of Chemical Bonding and Spontaneity through Student Explanation and Integration of Ideas', Journal of Research in Science Teaching, 39(6), pp. 464-496. doi: 10.1002/tea.10033.

Towns, M. H. and Robinson, W. R. (1993) 'Student Use of Test-Wiseness Strategies in Solving Multiple-Choice Chemistry Examinations', Journal of Research in Science Teaching, 30(7), pp. 709-722.

Tro, N. J. (2017) Chemistry. A Molecular Approach. Fourth ed. Pearson Education Limited.

Ünal, S. et al. (2006) 'A review of chemical bonding studies: needs, aims, methods of exploring students' conceptions, general knowledge claims and students' alternative conceptions', Research in Science \& Technological Education, 24(2), pp. 141-172. doi: $10.1080 / 02635140600811536$.

Utdanningsdirektoratet (2021) Kompetansemål etter kjemi 1 - Læreplan i kjemi (KJE01-02). Available at: https://www.udir.no/lk20/kje01-02/kompetansemaal-og-vurdering/kv532 (Accessed: 3 May 2021).

Venkataraman, B. (2017) 'Emphasizing the Significance of Electrostatic Interactions in Chemical Bonding', Journal of Chemical Education, 94(3), pp. 296-303. doi: 10.1021/acs.jchemed.6b00409.

Watson, J. R., Prieto, T. and Dillon, J. S. (1997) 'Consistency of students' explanations about combustion', Science Education, 81(4), pp. 425-443. doi: 10.1002/(sici)1098237x(199707)81:4<425::aid-sce4>3.0.co;2-e.

\section{APPENDIX 1}

The Norwegian version of the questions discussed in the article is given below.

\section{Question 1}

Bildet viser et ATP-molekyl der en binding er markert med en pil. Hvilket utsagn er SANT?<smiles></smiles> 
A) Det kreves alltid energi å bryte en binding. Det gjelder også for denne bindingen.

B) Det kreves energi for å bryte de fleste bindinger, men dette er en energirik binding som avgir energi når den brytes

C) Alle bindinger avgir energi når de brytes

D) Det kreves energi for å bryte kovalente bindinger, men dette er en ionebinding, og de avgir energi når de brytes

\section{Question 2}

Det avgis varme når hydrogen brenner i luft etter ligningen:

$$
2 \mathrm{H}_{2}+\mathrm{O}_{2} \rightarrow 2 \mathrm{H}_{2} \mathrm{O}
$$

Hva er årsaken til at det avgis varme?
A) Når hydrogenbindingene brytes, avgis det varme.
B) Når bindingene i oksygen brytes, avgis det varme.
C) Når bindingene mellom hydrogen og oksygen dannes, avgis det varme.
D) Både $a$ og b er rett.
E) Både $\mathrm{a}, \mathrm{b}$ og $\mathrm{c}$ er rett.

\section{APPENDIX 2}

The Norwegian version of the quotes from the student interviews is given below.

English: "Always" is kind of a don't-word, so I doubt that one immediately."

Norwegian: “"Alltid" er litt sånn ikke-ord, så den tviler jeg på med en gang."

English: "No, I think we take B. It seems more ... sensible. I don't ... I sort of think it is A, but B seems much more ... sensible, yes. Much more realistic."

Norwegian: "Nei, jeg tror vi kjører B. Den virker mer ... klok. Uten at jeg ... jeg tror det er litt A, men B virker mye mer ... klok, ja. Mye mer realistisk."

English: "I have never really heard the word high-energy bond before, so my gut feeling kind of want to choose that one, because I have never gotten a question like this before."

Norwegian: "Jeg har egentlig aldri hørt ordet energirik binding før, så magefølelsen min har litt lyst til å gå for det, siden jeg aldri har fått et sånt spørsmål før."

English: "I think energy is needed to break all bonds, if not they would just fall apart, maybe." Norwegian: "Jeg vil tro at det kreves energi for å bryte alle bindinger, hvis ikke hadde de bare falt fra hverandre, kanskje."

English: "Are there any bonds that don't need energy to break? I don't think so." Norwegian: "Er det noen bindinger som ikke trengs energi for å brytes? Tror jeg ikke." 
English: "I think that when the bonds are formed, it is an endothermic reaction, it needs energy. When they are broken, it is an exothermic reaction."

Norwegian: "Jeg vil tenke at når bindingene dannes, så blir det da en endoterm reaksjon, vil kreve energi. Når de brytes, så er det en eksoterm reaksjon." 